\title{
Cytokine Profiles in Acute Brucellosis, Compared with Those in Other
} Febrile Illnesses

\author{
Anahita Sanaei Dashti,, ${ }^{1,}$ Abdollah Karimi, ${ }^{2}$ Babak Elyasi, ${ }^{2}$ Ahmad Reza Shamshiri, ${ }^{3}$ Seyed Abdolmajid \\ Shoja, ${ }^{1}$ and Maryam Shamshiri ${ }^{2}$ \\ ${ }^{1}$ Shiraz HIV/AIDS Research Center, Institute of Health, Shiraz University of Medical Sciences, Shiraz, Iran \\ ${ }^{2}$ Pediatric Infectious Diseases Research Center, Shahid Beheshti University of Medical Sciences, Tehran, Iran \\ ${ }^{3}$ Dental Research Center, Dentistry Research Institute, Department of Community Oral Health, School of Dentistry, Tehran University of Medical Sciences, Tehran, Iran \\ "Corresponding author: Anahita Sanaei Dashti, Pediatric Department Office, Nemazee Hospital, Shiraz, Iran. Tel: +98-9017244313, Fax: +98-7136474303, E-mail: \\ anahita_sam@yahoo.com
}

Received 2016 May 01; Revised 2017 March 16; Accepted 2017 April 04.

\begin{abstract}
Background: It seems that activation of the T helper 1 (Th 1) cell response, including production of Interleukin-12 (IL-12) and Interferon-gamma (IFN- $\gamma$ ), leads to the resolution of disease and the dominance of Th 2 cells, and related cytokines like IL-4 may reduce the process of Brucella eradication.

Objectives: The aim of this study was to evaluate the levels of serum cytokines, IL-12, INF- $\gamma$, Tumor Necrosis Factor alpha (TNF- $\alpha$ ), and IL-4 in acute brucellosis and compare them with those in other febrile diseases.

Methods: This prospective cross-sectional study was done on 80 consecutive patients in Azerbaijan, Iran. The research defined 2 groups in the survey; (group 1) one group with brucellosis and the other group (group 2) without brucellosis; each consisting of 40 patients. All the patients had constitutional symptoms of fever, malaise, and anorexia. Serum agglutination and 2 ME ( 2 mercaptoethanol) tests were performed on the sera. Data were analyzed using the SPSS version 16 software.

Results: Serum TNF- $\alpha$ (group-1: $210.38 \pm 168.35$ and group-2: $19.53 \pm 16.36$ ), INF- $\gamma$ (group-1: $64.72 \pm 19.73$ and group-2: 12.18 \pm 5.37 ) and IL-12 (group-1: $283.10 \pm 253.51$ and group-2: $20.87 \pm 12.58$ ) levels were elevated significantly in brucellosis patients compared to the levels in other febrile patients (P value $\leq 0.001$ ). The IL-4 level showed no significant difference between brucellosis and other febrile patient's sera $($ P value $=0.870)$.

Conclusions: The current study showed that serum levels of Th 1 cytokines, including INF- $\gamma$ and IL-12 levels are elevated significantly in systemic brucellosis patients. However, IL-4 levels, a Th 2 cytokine, had no significant difference between the 2 groups.
\end{abstract}

Keywords: Cytokines, Interferon Gamma, Interleukin-12, Tumor Necrosis Factor-alpha, Interleukin-4, Brucellosis

\section{Background}

Brucellosis, a chronic granulomatous infection caused by organisms of the genus Brucella, continue to be a major public health problem worldwide, especially in the Middle East region. In Iran, the infection rate of brucellosis is approximately 43.24 per 100000 people, annually (1). In addition to paucity of physical findings, brucellosis causes many vague and nonspecific symptoms that make the diagnosis more challenging. Furthermore, brucellosis is still a challenging disease regarding its pathophysiology. After entry and invasion of the mucus membrane, brucella intelligently organizes a series of processes and interactions within immune system cells that allow for its persistence and infectivity. The response against brucella involves the entire immune system, from innate to adaptive immunity. It's noteworthy to mention that cytokines have a crucial role in brucella pathogenesis and they probably regulate host's susceptibility or resistance to brucella $(2,3)$. Through the activation of T helper 1 (Th 1 ) cell response cytokines, Interleukin 12 (IL-12) and interferon-gamma (INF$\gamma$ ) are produced leading to macrophage activation and parasite clearance $(4,5)$. The IFNG $+874 \mathrm{~A} / \mathrm{A}$ polymorphism is associated with lower production of INF- $\gamma$. Individuals, who are homozygous for the +847 A allele, are susceptible to brucellosis, which indicates the importance of INF- $\gamma$ in brucellosis $(6,7)$. In addition, it seems that susceptibility to brucella is probably the result of activation of Th 2 cells that inhibit $\mathrm{T}$ cells activation and reduce the process of activation of macrophages, and their ability to eradicate the microbe $(8,9)$. It has been demonstrated that IL-4 and also deficiency in IL-12 decrease INF- $\gamma$ production and increase the susceptibility to brucella infection $(10,11)$.

A number of studies have addressed the role of IFN- $\gamma$

Copyright (c) 2017, Archives of Clinical Infectious Diseases. This is an open-access article distributed under the terms of the Creative Commons Attribution-NonCommercial 4.0 International License (http://creativecommons.org/licenses/by-nc/4.0/) which permits copy and redistribute the material just in noncommercial usages, provided the original work is properly cited. 
and IL-12 in acute human brucellosis $(4,8,12)$ yet little information is available regarding the role of Tumor Necrosis Factor-alpha (TNF- $\alpha$ ) and IL- 4 as a Th 2 cytokine, in human brucellosis (2). Therefore, this study assessed IL-4, TNF- $\alpha$, IFN- $\gamma$, and IL-12 levels as valuable candidates of Th1 and Th2 responses for evaluation of immunological responses in brucella-infected patients.

\section{Methods}

This prospective cross-sectional study was performed from 2010 to 2011. It was accomplished in Azerbaijan, a North West province of Iran that is endemic for brucellosis. The study was approved by the ethics committee of Shahid Beheshti University of Medical Sciences (number: 263) and informed consents were obtained from all patients.

All patients with symptoms of brucellosis from outpatient offices in the entire city were referred to the central laboratory. Patients with constitutional symptoms of fever, malaise and anorexia, arthritis, arthralgia, and body ache were diagnosed by doctors and included in the study. Serum (standard) agglutination (SAT) and 2 mercaptoethanol (2 ME) tests were performed on all sera of patients for confirmation of diagnosis. In the current study the patients were divided to 2 groups; those with serum agglutination titer of $>1 / 80$ and a 2 ME titer of $>1 / 20$ as the brucellosis group (group-1), and other febrile patients with SAT of less than 1/80 and 2 ME of less than 1/20 were considered as the control group (group-2). Samples were collected consecutively to reach the desired number of patients in each group (40 cases).

Two milliliters of blood was collected from all cases and preserved after serum extraction till the performance of the serologic tests. To prevent the "Prozone phenomenon", the sera were diluted from $1 / 20$ to $1 / 5120$. The samples were sent to the pediatric infectious diseases research center of Mofid children's hospital for cytokines measurement. Serum cytokines including TNF- $\alpha$, INF- $\gamma$, IL-12, and IL-4 were measured by the enzyme linked immunosorbent assay (ELISA) method, using the "human interleukin elisa 13MS223 R 13MS22314" kit. The minimum sensitivity rates to detect cytokines were $2.3 \mathrm{pg} / \mathrm{mL}, 0.99 \mathrm{pg} / \mathrm{mL}, 1.2 \mathrm{pg} / \mathrm{mL}$, and $1.3 \mathrm{pg} / \mathrm{mL}$, for TNF- $\alpha$, INF- $\gamma$, IL-12, and IL-4, respectively.

\subsection{Statistical Analysis}

All Statistical analyses were performed using the SPSS software version 16.0. Descriptive data were expressed as frequencies and percentages and quantitative data were described with mean + SD. the normality of variables was checked by the Kolmogorov-Smirnov test and then independent samples t-test and Mann-Whitney U test were used for comparison of means for continuous variables. A P value of less than 0.05 was considered significant.

\section{Results}

This study included 80 patients, 40 with brucellosis and 40 without it. In the former, $40 \%$ and in the latter $52.5 \%$ were male (Figure 1). Mean age in brucellosis patients was $36.9+15.1(\min =4, \max =67)$ years and in the other patients it was $36.8+15.4($ minimum $=5$ and maximum $=70)$ years (P value: 0.971 ).

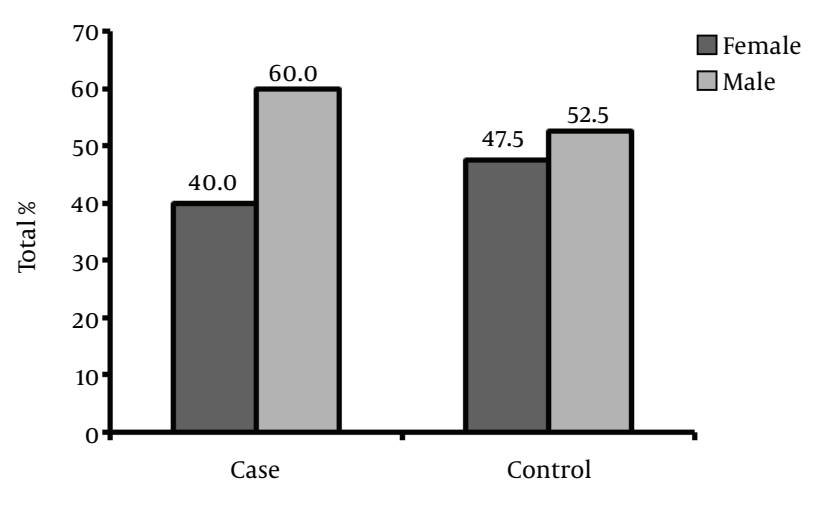

Figure 1. Gender Distribution of the Patients and the Control Group

Figure 2. Serum Interleukin-12 Levels in the Study Groups

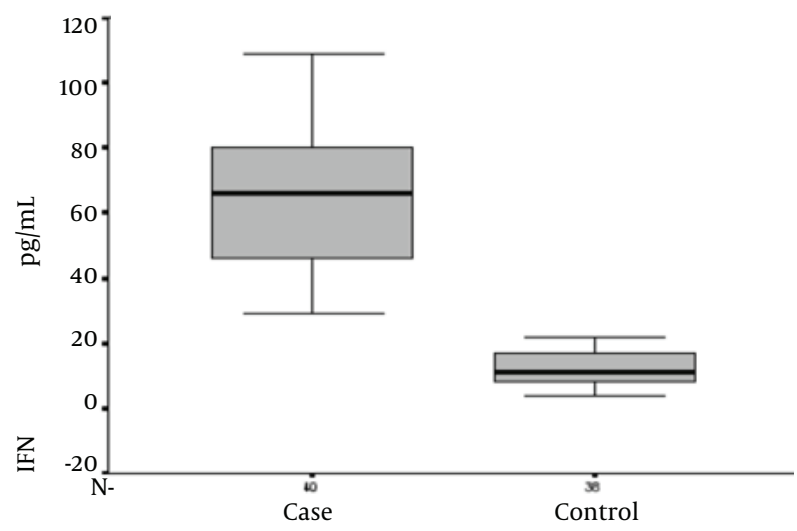

Results are means $\pm S D,{ }^{*} \mathrm{P}<0.05$

Furthermore, TNF- $\alpha$, INF- $\gamma$, and IL-12 levels were elevated significantly in brucellosis patients compared to the levels in the other febrile patients, yet no significant difference was observed in IL- 4 level between the 2 groups (Table 1). Serum levels of cytokines are shown in Table 1. 
Table 1. Serum Levels of Cytokines Between the Two Groups

\begin{tabular}{|c|c|c|c|c|c|c|c|}
\hline \multirow[t]{2}{*}{ Parameter } & \multicolumn{3}{|c|}{ Case $(n=40)$} & \multicolumn{3}{|c|}{$\operatorname{Control}(n=40)$} & \multirow[t]{2}{*}{ PValue } \\
\hline & Mean & SD & Median & Mean & SD & Median $^{a}$ & \\
\hline TNF- $\alpha$ & 210.4 & 168.3 & $162(49-361.2)$ & 19.1 & 16.1 & $14(10.2-14)$ & $0.001^{b}$ \\
\hline IL-4 & 49 & 17.7 & $50(39.7-45)$ & 49.6 & 12.9 & $49.5(41.5-63)$ & $0.870^{c}$ \\
\hline INF- & 64.7 & 19.7 & $66(45-80)$ & 12.2 & 5.3 & $11(8-17)$ & $0.001^{\mathrm{b}}$ \\
\hline IL-12 & 283.1 & 253.5 & $229(149.2-342.5)$ & 21.3 & 12.7 & $18.5(11-29.2)$ & $0.001^{\mathrm{b}}$ \\
\hline
\end{tabular}

a (interquartile range in parentheses).

b Mann-Whitney U test.

${ }^{\mathrm{c}}$ Independent sample t-test.

Figure 3. Serum Interferon-Gamma Levels in the Study Groups

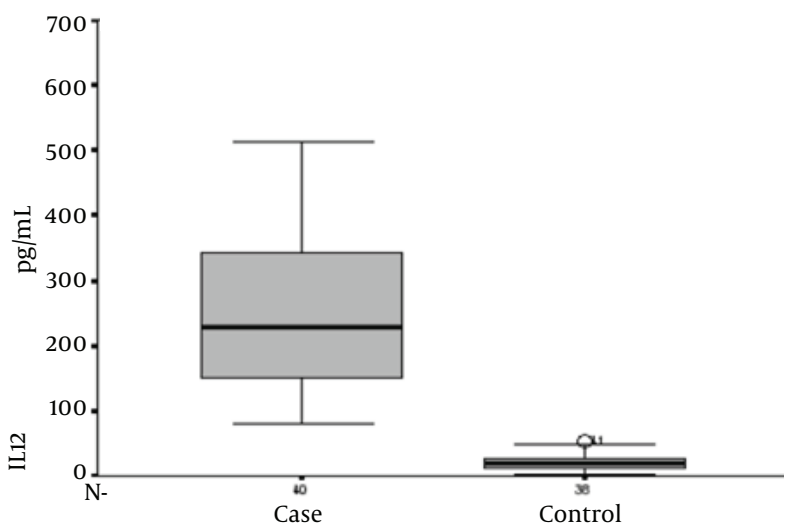

Results are means $\pm \mathrm{SD},{ }^{*} \mathrm{P}<0.05$

Figure 4. Serum Tumor Necrosis Factor Alpha Level in the Study Groups

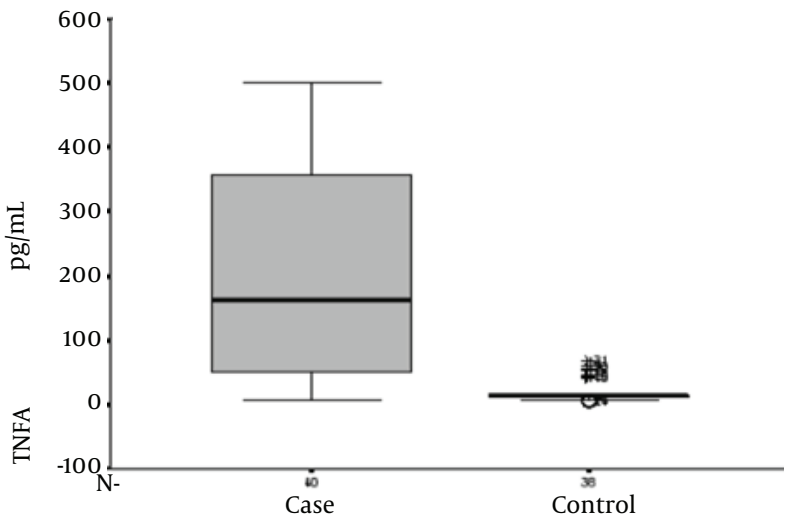

Results are means $+\mathrm{SD},{ }^{*} \mathrm{P}<0.05$

Serum IL-12 levels were $283.10+253.51$ and $20.87+12.58$ in brucellosis and control groups, respectively (P value $\leq$
Figure 5. Serum Interleukin-4 levels in the study groups

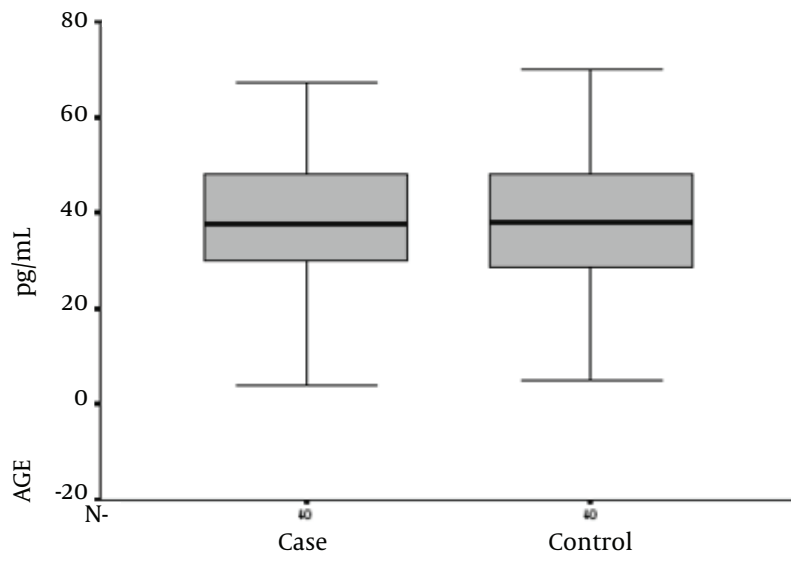

Results are means $+\mathrm{SD},{ }^{*} \mathrm{P}<0.05$

0.001). Serum IFN- $\gamma$ levels were $64.72+19.73$ and $12.18+5.37$ in brucellosis and the control groups, respectively ( $\mathrm{P}$ value $\leq$ 0.001). Serum TNF- $\alpha$ level was $210.38+168.35$ and 19.53 +16.36 in brucellosis and the control groups, respectively ( $P$ value $\leq 0.001)$. Serum IL-4 levels were $49.0+17.73$ and $49.58+12.99$ in brucellosis and control groups, respectively $(\mathrm{P}$ value $=0.870)$.

\section{Discussion}

Brucellosis is a febrile illness with various and nonspecific signs and symptoms, including high fever, night sweats, and joint pain that can make its diagnosis difficult (13). Also, skeletal system involvement is common in brucellosis and its incidence is altered from $11 \%$ to $85 \%$ in different reports (14).

Brucellosis is a disease with a complex immunopathogenesis and the pathogen mechanisms of brucella and other features remain unclear. It has been suggested that 
the balance between Th 1 and $T h 2$ cytokines plays an important role in brucellosis and TNF- $\alpha$, INF- $\gamma$, and IL-12 are considered as key cytokines in this respect (3). Brucella infection in mice provokes a type 1 (Th1) immune response, that leads to elimination of the microorganism and termination of the infection that is mediated by major cytokines, including TNF-a, IFN- $\gamma$, and IL-12 (8).

Interleukin-12, a key cytokine, promoting Th 1 differentiation and resultant immune responses, is produced and secreted by B cells and macrophages and stimulates $\mathrm{T}$ cells to synthesize and secrete IFN- $\gamma$ and increase cytotoxic activity. This cytokine is also required for the stimulation of Natural Killer cells (NK), to produce IFN- $\gamma$ (15). The enhanced activation of $\mathrm{T}$ and NK cells by IL-12 has been shown to contribute to the control of infection. Besides, IFN- $\gamma$ activates bactericidal function of macrophages, and limits brucella infection both in vitro and in vivo $(4,16)$. It was previously demonstrated that Leishmania majorsusceptible BALB/c mice, which received recombinant IL-12, had the ability to control the infection. This protective effect of IL-12 is reversible by the neutralization of IFN- $\gamma$ (17).

According to Zhan et al.'s study, reduction in IL-12 in mice with Brucella abortus significantly intensifies brucella infection. Also, administration of anti-IL-12 before infection significantly exacerbated the infection, and numbers of brucella in the spleen and liver cells were 20- to 40-fold higher in mice treated with anti-IL-12 than those in isotype control globulin-treated mice (4). Consistent with previous studies, the serum levels of IL-12 increased in the patients with brucellosis, compared with the levels in the controls $(12,18)$.

In addition, the serum level of IFN- $\gamma$ increased in patients with active brucellosis. Furthermore, IFN- $\gamma$, the main cytokine responsible for activating macrophages, is produced mainly by $\mathrm{CD} 4$ and $\mathrm{NK}$ cells or in response to IL-12. Its role is particularly imperative in killing phagocytized intracellular microbes, thus, it also plays a critical role in the pathogenesis of brucellosis $(19,20)$. Once produced, it leaves remarkable effects on the immune system, including activating the macrophages, inducing the synthesis of reactive oxygen species, and nitrogen intermediates. It also increases apoptosis, cell differentiation, and cytokine production.

Typically, serum levels of IFN- $\gamma$ are reported to increase in patients with brucellosis $(1,2,18,19)$. In a study by Demirdag, mean IFN- $\gamma$ values appeared to be significantly higher in acute brucellosis compared to that in control group.

In response to inflammation and infection, TNF- $\alpha$ is produced mainly from macrophages and probably plays an important role in resistance to infection with intracellular bacteria. This cytokine could act as a stimulator of
IFN- $\gamma$ secretion by NK cells from severe combined immunodeficiency (SCID) splenocytes in vitro (15). Even though the exact role of the cytokine, regarding Th 1 is not clear, an in vitro research with ovalbumin-specific T-cell receptor transgenic mice concluded that TNF- $\alpha$ had no direct effect on the induction of Th 1 responses (21).

The important role of TNF- $\alpha$ in immunity against brucella was confirmed when in a research on TNF- $\alpha$ depleted mice with the polyclonal antibody, the numbers of brucella per gram of the spleen or liver were more than 10 folds higher than those in control infected mice (10). Two weeks after infection in this TNF- $\alpha$ depleted mice, the infection aggravated, yet it recovered in 6 weeks after infection in the controls. Interestingly, IL-12 depleted mice did not show any significant improvement 6 weeks after infection with brucella (P, 0.001) (10).

According to a few published articles, there are conflicting results about changes in the serum levels of TNF- $\alpha$ in brucellosis. Ahmed K et al. reported undetectable levels of TNF- $\alpha$ in the serum of patients with acute brucellosis. In a research performed on 67 cases, 37 patients with brucellosis and 30 healthy individuals with no history of brucella infection, serum TNF- $\alpha$ levels were unchanged compared to healthy controls (12). In another study on humans, brucella infected macrophages produced IL-1, IL-6, IL-10 and other chemokines like IL-8 yet did not secrete TNF- $\alpha(16,22)$.

In contrast to the aforementioned study and in agreement with the present study, serum TNF- $\alpha$ levels were significantly higher in the acute phase of brucellosis compared with levels in the post-treatment and the control group in a study from Turkey. This increased level of TNF$\alpha$ was also correlated with increased levels of IFN- $\gamma$ in the acute phase of the disease (2). Akbulutet al. also reported that TNF- $\alpha$ levels after treatment were significantly lower than that in pre-treatment $(\mathrm{P}<0.001)(23)$.

Although the definite role of IL-4 in human brucellosis is not understood clearly (2), as the main cytokine of the Th 2 system and the key stimulant of the production of Ig $\mathrm{E}$ antibodies, it deserves more investigations in brucellosis. Furthermore, CD4 T lymphocytes of the Th 2 subset and activated mast cells are the main cellular producers of IL-4. According to Galanakis et al., serum IL-4 levels increased in the acute phase of brucellosis in children. Deterioration of the disease process was attributed to increased levels of this cytokine causing a reduction in brucella immunity through extreme Th 2 response. In Rafeie et al.'s study, IL-4 were not secreted in response to heat-inactivated Rev1 bacteria (24). In another research by Demirdag et al., (2) serumIL-4 levels were relatively low and did not significantly differ from that of the control group, consistent with the current study.

As shown by previous studies, the Th1 response was 
dominant in patients with acute brucellosis (18). In this study, serum levels of Th1 system cytokines significantly increased in acute brucellosis, yet the serum level of IL-4 showed no surge in this setting. It is notable that the brucellosis patients were compared with those with febrile issues.

\section{Acknowledgments}

The authors thank the pediatric infections research center affiliated to Shahid Beheshti University of Medical Sciences, Tehran, Iran for their financial support of this research. Dr Hassan Khajehei is also acknowledged for copy editing of the manuscript.

\section{Footnotes}

Authors' Contribution: Study concept and design: Anahita Sanaei Dashti and Abdollah Karimi; acquisition of data: Babak Elyasi; analysis and interpretation of data: Ahmad Reza Shamshiri and Babak Elyasi; drafting of the manuscript: Abdollah Karimi and Seyed Abdolmajid Shoja; critical revision of the manuscript for important intellectual content: Abdollah Karimi and Anahita Sanaei Dashti; statistical analysis: Ahmad Reza Shamshiri; study supervision: Anahita Sanaei Dashti.

Financial Disclosure: There were no financial interests related to the material in the manuscript.

Funding/Support: This study was supported by the pediatric infections research center affiliated to Shahid Beheshti University of Medical Sciences, Tehran, Iran.

\section{References}

1. Mostafavi E, Asmand M. Trend of brucellosis in Iran from 1991 to 2008. Iran J Epidemiol. 2012;8(1):94-101.

2. Demirdag K, Ozden M, Kalkan A, Godekmerdan A, Sirri Kilic S. Serum cytokine levels in patients with acute brucellosis and their relation to the traditional inflammatory markers. FEMS Immunol Med Microbiol. 2003;39(2):149-53. [PubMed:14625098].

3. Galanakis E, Makis A, Bourantas KL, Papadopoulou ZL. Interleukin-3 and interleukin-4 in childhood brucellosis. Infection. 2002;30(1):33-4. [PubMed: 11876513].

4. Zhan Y, Cheers C. Endogenous interleukin-12 is involved in resistance to Brucella abortus infection. Infect Immun. 1995;63(4):1387-90. [PubMed: 7890399].

5. Golding B, Scott DE, Scharf O, Huang LY, Zaitseva M, Lapham C, et al. Immunity and protection against Brucella abortus. Microbes Infect. 2001;3(1):43-8. [PubMed: 11226853].

6. Bravo MJ, de Dios Colmenero J, Alonso A, Caballero A. Polymorphisms of the interferon gamma and interleukin 10 genes in human brucellosis. Eur J Immunogenet. 2003;30(6):433-5. [PubMed: 14675398].
7. Rasouli M, Kiany S, Alborzi A. Polymorphism in the first intron of interferon gamma gene $(+874 \mathrm{~T}, \mathrm{~A})$ in Iranian patients with brucellosis. Iran J Immunol. 2005;2(4):226-31.

8. Jiang X, Baldwin CL. Effects of cytokines on intracellular growth of Brucella abortus. Infect Immun. 1993;61(1):124-34. [PubMed: 8418034].

9. Fernandes DM, Baldwin CL. Interleukin-10 downregulates protective immunity to Brucella abortus. Infect Immun. 1995;63(3):1130-3. [PubMed: 7868238].

10. Zhan Y, Liu Z, Cheers C. Tumor necrosis factor alpha and interleukin12 contribute to resistance to the intracellular bacterium Brucella abortus by different mechanisms. Infect Immun. 1996;64(7):2782-6. [PubMed: 8698508].

11. Scharf O, Agranovich I, Lee K, Eller NL, Levy L, Inman J, et al. Ontogeny of Th1 memory responses against a Brucella abortus conjugate. Infect Immun. 2001;69(9):5417-22. [PubMed: 11500412].

12. Ahmed K, Al-Matrouk KA, Martinez G, Oishi K, Rotimi VO, Nagatake T. Increased serum levels of interferon-gamma and interleukin-12 during human brucellosis. Am J Trop Med Hyg. 1999;61(3):425-7. [PubMed: 10497984].

13. Kazak E, Akalin H, Yilmaz E, Heper Y, Mistik R, Sinirtas M, et al. Brucellosis, a retrospective evaluation of 164 cases. Singapore Med J. 2016;57(11):624-9. doi:10.11622/smedj.2015163. [PubMed: 26768063].

14. Sanaei Dashti A, Karimi A. Skeletal involvement of Brucella melitensis in children, A systematic review. Iran J Med Sci. 2013;38(4):286-92. [PubMed: 24293781].

15. Tripp CS, Wolf SF, Unanue ER. Interleukin 12 and tumor necrosis factor alpha are costimulators of interferon gamma production by natural killer cells in severe combined immunodeficiency mice with listeriosis, and interleukin 10 is a physiologic antagonist. Proc Natl Acad Sci U S A. 1993;90(8):3725-9. [PubMed: 8097322].

16. Dornand J, Gross A, Lafont V, Liautard J, Oliaro J, Liautard JP. The innate immune response against Brucella in humans. Vet Microbiol. 2002;90(1-4):383-94. [PubMed: 12414158].

17. Sypek JP, Chung CL, Mayor SE, Subramanyam JM, Goldman SJ, Sieburth DS, et al. Resolution of cutaneous leishmaniasis: interleukin 12 initiates a protective $\mathrm{T}$ helper type 1 immune response. J Exp Med. 1993;177(6):1797-802. [PubMed: 8098733].

18. Giambartolomei GH, Delpino MV, Cahanovich ME, Wallach JC, Baldi PC, Velikovsky CA, et al. Diminished production of Thelper 1 cytokines correlates with T cell unresponsiveness to Brucella cytoplasmic proteins in chronic human brucellosis. JInfect Dis. 2002;186(2):252-9. doi: 10.1086/341449. [PubMed:12134263].

19. Pappas G, Akritidis N, Bosilkovski M, Tsianos E. Brucellosis. N Engl J Med. 2005;352(22):2325-36. doi: 10.1056/NEJMra050570. [PubMed: 15930423].

20. Zhan Y, Cheers C. Endogenous gamma interferon mediates resistance to Brucella abortus infection. Infect Immun. 1993;61(11):4899901. [PubMed: 8406893].

21. Hsieh CS, Macatonia SE, O'Garra A, Murphy KM. Pathogen-induced Th1 phenotype development in CD4+ alpha beta-TCR transgenic T cells is macrophage dependent. Int Immunol. 1993;5(4):371-82. [PubMed: 8494824].

22. Refik M, Mehmet N, Durmaz R, Ersoy Y. Cytokine profile and nitric oxide levels in sera from patients with brucellosis. Braz J Med Biol Res. 2004;37(11):1659-63. [PubMed: 15517081].

23. Akbulut H, Celik I, Akbulut A. Cytokine levels in patients with brucellosis and their relations with the treatment. Indian J Med Microbiol. 2007;25(4):387-90. [PubMed: 18087091].

24. Rafiei A, Ardestani SK, Kariminia A, Keyhani A, Mohraz M, Amirkhani A. Dominant Th1 cytokine production in early onset of human brucellosis followed by switching towards Th2 along prolongation of disease. J Infect. 2006;53(5):315-24. doi: 10.1016/j.jinf.2005.11.024. [PubMed: 16488475]. 